\title{
PENERAPAN K3RS DALAM UPAYA PERAWAT MEMINIMALISIR PENYAAKIT AKIBAT BEKERJA SEBAGAI SEORANG PERAWAT
}

Nabila Rahmadhani / 191101133

Rahmadhaninabila2@gmail.com

\begin{abstract}
The hospital is a workplace that has a high risk of accidents at work. Good knowledge of occupational health and safety (K3) can reduce the number of accidents at work to achieve zero accidents. Occupational safety and health are activities designed to ensure safety and health in the workplace. Nurses are at risk for accidents and occupational diseases. However, there is no relationship between years of service and work accidents. It is hoped that the hospital management will improve the quality of training and supervision and reinforce the rules that have been made by giving heavy sanctions to workers who have violated the rules.
\end{abstract}

Kyewords: occupational health and safety (K3), how to prevent disease caused by the work of nurses

\begin{abstract}
Abstrak
Rumah sakit merupakan tempat kerja yang berisiko tinggi untuk terjadinya kecelakaan kerja. Pengetahuan kesehatan dan keselamatan kerja (K3) yang baik dapat menurunkan angka kecelakaan kerja hingga tercapainya zero accident. Keselamatan dan kesehatan kerja adalah kegiatan yang dirancang untuk menjamin keselamatan dan kesehatan di tempat kerja. Perawat berisiko terhadap kecelakaan dan penyakit akibat pekerjaan. Namun tidak ada hubungan masa kerja dengan Kecelakaan Kerja. Diharapkan pihak manajemen rumah sakit agar meningkatkan kualitas dari pelatihan dan pengawasan serta mempertegas aturan yang telah dibuat dengan cara memberikan sanksi berat kepada pekerja yang didapat melanggar aturan.
\end{abstract}

Kata kunci: kesehatan dan keselamatan kerja (K3), cara pencegahan penyakit akibat kerja perawat 


\section{Metode}

Metode yang di gunakan dalam kajian ini adalah metode literature review, di mana pada kajian ini di buat berdasarkan berbagai suber bacaan yang berupa, buku bacaan , jurnal, tesis juga maupun ebook yang berhubunga dengan keselamatan dan kesehatan Kerja, upaya dalam meminimalisir penyakit yang disebabkan oleh pekerjaan seorang perawat, serta kejadian kejadian yang berhubungan dengan K3RS.

Kajian ini juga merupakan kajian bebas diman adalam kajian ini bersifat bebas dimana kajian ini juga di buat dengan cara perbandingan dengan artikel satu dengan artikel arrikel yang lainnya dan menghasilkan perbandingan yang di tulis secara berurutan dan bertauran dalam hasil kajian ini.

\section{Hasil}

Hasil dari metode ini adalah Pelaksanaan Keselamatan dan Kesehatan Kerja (K3) adalah salah satu bentuk upaya untuk menciptakan tempat kerja yang aman, sehat, bebas dari pencemaran lingkungan, sehingga dapat mengurangi dan bebas dari kecelakaan kerja dan penyakit akibat kerja yang pada akhirnya dapat meningkatkan efisiensi dan produktivitas kerja.

Namun dalam penerapan Keselamatan dan Kesehatan Kerja (K3) masih juga banyak didapati perawat perawat yang terkena penyakit akibat kerja yang di lakukan di klinik, rumah sakit atau instansi kesehatan lainnya. Oleh sebab itu Keselamatan dan Kesehatan Kerja di rumah sakit harus lebih memperhatikan dari program tersebut agar kejadia perawat yang terkena penyakit di saat melakukan tugas sebagai seorang perawat dapat di minimalisir ke beradaannya atau sampai tercapainya zero accident.

Faktor-faktor yang harus di perhatikan juga harus menjadi kunci dalam pengembangan k3 di rumah sakit. Serta pengetahuan perawat tentang $\mathrm{k} 3$ juga harus di tingkatkan karena pengetahuan adalah kunci untuk menjadikan perawat lebih profesional dalam melakukan tugasnya di dunia kesehatan.

Pencegahan \& pengendalian infeksi juga sangat di butuhkan di rumah sakit. PPI ini berfungsi untuk mengurani penyebaran infeksi yang terkait dengan pelayanan kesehatan,dengan penilaian, perencanaan dan evaluasi oleh national infection control policies. Serta mendukung promosi kualitas 
pelayanan kesehatan yang aman bagi pasien, petugas kesehtan dan orang lain dalam perawatan kesehatan dan lingkungan dengan cara yang hemat biaya. Sehingga PPI ini sangat di butuhkan di rumah sakit.

\section{Latar belakang}

Peningkatan sumber daya manusia yang bermuara pada produktifitas kerja, merupakan dambaan setiap instansi atau perusahaan yang sedang beroperasi. pekerja yang terampil, ulet, berkompeten serta memiliki loyalitas, merupakan modal yang tak ternilai bagi instansi itu sendiri, kemajuan suatu instansi atau perusahaan salah satunya ditentukan oleh sumber daya manusia yang ada di dalamnya, sehingga kewajiban untuk tetap menjaga serta meningkatkan derajat kesehatan serta keselamatan para pekerja, harus menjadi yang utama. Pelaksanaan keselamatan dan kesehatan Kerja (K3) adalah salah satu bentuk upaya untuk menciptakan tempat kerja yang aman, sehat, bebas dari pencemaran lingkungan, sehingga dapat mengurangi kecelakaan kerja dan penyakit akibat kerja. Dalam, pasal 23, penjelasan undang-undang nomor 23 tahun 1992 tentang kesehatan menjelaskan bahwa upaya kesehatan harus diselenggarakan di semua tempat kerja, khususnya tempat kerja yang mempunyai risiko bahaya kesehatan, mudah terjangkit penyakit atau mempunyai karyawan paling sedikit 10 orang (Depkes. 2009).

Kesehatan dan Keselamatan Kerja (K3) adalah upaya untuk memberikan jaminan keselamatan dan meningkatkan derajat kesehatan pekerja dengan cara pencegahan kecelakaan dan penyakit akibat kerja (PAK), pengendalian bahaya di tempat kerja, promosi kesehatan, pengobatan, dan rehabilitasi. Berdasar atas data Badan Penyelenggara Jaminan Sosial (BPJS) Ketenagakerjaan, hingga akhir 2015 telah terjadi kecelakaan kerja sebanyak 105.182 kasus di Indonesia. Jumlah kecelakaan akibat kerja di Jawa Barat pada tahun 2014 mencapai 1713 kasus dan di Pulau Jawa sebesar 4.663 kasus. Kecelakaan kerja dapat dipengaruhi oleh lama kerja, usia, dan pendidikan seseorang. Data Bureau of Labour Statistics menyebutkan sebanyak 253.700 kecelakaan kerja terjadi di rumah sakit Amerika Serikat pada tahun 2011.8 Kecelakaan kerja yang terjadi di rumah sakit dapat berupa tertusuk jarum suntik, cedera muskuloskeletal, dan stres psikis.

Pelaksanaan Keselamatan dan Kesehatan Kerja (K3) adalah salah satu bentuk upaya untuk menciptakan tempat kerja yang aman, sehat, bebas dari pencemaran lingkungan, sehingga dapat mengurangi dan bebas dari kecelakaan kerja dan penyakit akibat kerja yang pada akhirnya 
dapat meningkatkan efisiensi dan produktivitas kerja.

Hasil laporan National Safety Council (NSC) tahun 2008 menunjukan bahwa terjadinya kecelakaan kerja di Rumah Sakit $41 \%$ lebih besar dari industri lain,kasus yang sering terjadi adalah tertusuk jarum, terkilir, sakit pinggang, tergores, terpotong, luka bakar, penyakit infeksi dan lain-lain

Organisasi Buruh Internasional atau International Labour Organization (ILO) merupakan suatu organisasi yang menaungi permasalahan K3 di tingkat dunia. Menurut ILO pelaksanaan K3 ditujukan untuk mencegah kecelakaan kerja dan penyakit yang ditimbulkan oleh suatu pekerjaan.20 Permasalahan K3 juga diatur oleh Organisasi Kesehatan Dunia atau World Health Organization (WHO).

Penerapan K3 di Indonesia diatur oleh UndangUndang Republik Indonesia Nomor 13 Tahun 2003 tentang Ketenagakerjaan, sedangkan K3 rumah sakit (K3RS) diatur oleh KEPMENKES RI Nomor 1087/MENKES/SK/VIII/2010. K3 pada umumnya bertujuan melindungi keselamatan dan kesehatan pekerja ataupun buruh dalam mewujudkan produktivitas kerja yang optimal. Tujuan diterapkannya K3RS adalah terciptanya cara kerja, lingkungan kerja yang sehat, aman, nyaman, dan dalam rangka meningkatkan

derajat kesehatan karyawan RS. Pengetahuan K3RS yang baik diharapkan mampu menekan angka kecelakaan kerja karena individu tersebut dapat menerapakan tindakan yang sesuai dengan pengetahuan $\mathrm{K} 3$ yang dimilikinya.

\section{Pembahasan}

Menurut keputusan Menteri Kesehatan Republik Indonesia No.432/ MENKES/SK/IV/2007 Tentang Pedoman Kesehatan dan Keselamatan Kerja di Rumah Sakit, komitmen diwujudkan dalam bentuk kebijakan (policy) tertulis, jelas dan mudah dimengerti serta diketahui oleh seluruh karyawan Rumah Sakit.

Tujuan manajemen hiperkes dan K3RS adalah melindungi petugas RS dari risiko PAK/PAHK/KAK serta dapat meningkatkan produktivitas dan citra RS, baik dimata konsumen maupun pemerintah. Keberhasilan pelaksaanaan K3RS sangat tergantung dari komitmen tertulis dan kebijakan pihak direksi. Pelaksanaan K3 di rumah sakit ditujukan pada 3 hal utama yaitu SDM, lingkungan kerja dan pengorganisasian $\mathrm{K} 3$ dengan menggalakkan kinerja P2K3 (Panitia Pembina atau Komite K3) di Rumah Sakit. (Athifah A.N, 2014)

Setiap Rumah Sakit wajib melaksanakan pelayanan kesehatan dan keselamatan kerja sesuai yang tercantum pada pasal 23 dalam 
Undang-Undang No. 36 tahun tahun 2009 tentang kesehatan dan Peraturan Menteri Tenaga Kerja dan Transmigrasi RI No.03/MEN/1982 tentang pelayanan kesehatan kerja.

Upaya penerapan K3 di rumah sakit menyangkut tenaga kerja, cara/metode kerja, alat kerja, proses kerja, dan lingkungan kerja yang meliputi peningkatan, pencegahan, pengobatan, dan pemulihan. Tenaga kesehatan yang sering berkontak langsung dengan pasien adalah perawat. Tingkat pengetahuan K3 perawat sangat penting dalam menjaga keselamatan pasien dan diri perawat itu sendiri sesuai dengan penelitian terdahulu bahwa didapatkannya hubungan bermakna antara tingkat pengetahuan perawat dengan tindakan keselamatan terhadap pasien

Penyakit Akibat Kerja adalah penyakit yang disebabkan oleh pekerjaan dan lingkungan kerja. Faktor risiko PAK antara lain: Golongan fisik, kimiawi, biologis atau psikososial di tempat kerja. Faktor tersebut di dalam lingkungan kerja merupakan penyebab yang pokok dan menentukan terjadinya penyakit akibat kerja. Faktor lain seperti kerentanan individual juga berperan dalam perkembangan penyakit di antara pekerja yang terpajan

Faktor Predisposing
Faktor predisposing (pencetus) (pengetahuan, sikap. Kepercayaan dan nilai) pada perawat terhadap K3RS yaitu memiliki hubungan yang sangat berpengaruh terhadap keselamatan dan kesehatan kerja pada perawat dalam penanganan pasien. Seluruh komponen berkorelasi sangat baik, sedangkan nilai tertinggi pada indikatornya adalah komponen kepercayaan, artinya bahwa kepercayaan memiliki nilai yang sangat baik dan memiliki pengaruh yang sangat baik terhadap perilaku seseorang, sedangkan nilai untuk pengetahuan adalah yang paling rendah.

\section{Faktor Reinforcing}

Faktor reinforcing (pendorong) (petugas yang menjadi contoh) pada perawat terhadap K3RSHasil uji statistik nilai faktor reinforcing (petugas yang menjadi contoh) ini tidak berpengaruh terhadap keselamatan dan kesehatan kerja pada perawat dalam penanganan pasien. Hal ini mungkin terjadi karena petugas yang bertanggung jawab kurang melaksanakan tugas $\mathrm{K} 3$ sebagai akibat tugas rangkap, maka bila telah dilaksanakan dengan kesadaran sendiri faktor pendorong kurang berarti, sehingga tidak berpengaruh terhadap keselamatan dan kesehatan kerja.

Faktor Enabling 
Faktor enabling (fasilitas keamanan dan keselamatan, hukum/aturan) pada perawat terhadap K3RS. Faktor enabling berpengaruh terhadap K3 pada perawat dalam penanganan sebagai faktor yang memungkinkan suatu proses perilaku, maka faktor ini memiliki kedudukan yang cukup strategis di mana perubahan tidak dapat terjadi bila faktor ini tidak disiapkan fasilitas pendukungnya. Nilai yang paling tinggi pada faktor enabling berada pada komponen hukum/aturan karena pada prinsipnya perilaku seseorang dipengaruhi oleh aturan yang ada di lingkungannya.

\section{Factor Core and Care}

Factor core and care. Faktor core, and care (hubungan interpersonal dan kepedulian) berpengaruh terhadap keselamatan dan kesehatan kerja pada perawat dalam penanganan pasien. Core, and care, namun pada hasil outer wight nilai yang paling tinggi adalah core, sedangkan care tidak signifikan, hal ini mungkin dipengaruhi oleh indikator care yang kurang variasi dalam pertanyaan dalam instrument indikator kepedulian tidak mempunyai nilai yang bermakna.

Pengawasan adalah kegiatan manajer yang mengusahakan agar pekerjaan terlaksana sesuai rencana yang ditetapkan dan hasil yang dikehendaki. Agar pengawasan berhasil maka manajer harus melakukan kegiatan pemeriksaan, pengecekan, pengcocokan, inspeksi, pengendalian dan berbagai tindakan yang sejenis. Pengawasan adalah suatu pekerjaan yang berarti mengarahkan yaitu memberi tugas, menyediakan intruksi, pelatihan dan nasihat kepada individu juga termasuk mendengarkan dan memecahkan masalah yang berhubungan dengan pekerjaan serta menanggapi keluhan bawahan

\section{Pencegahan}

Berikut ini adalah penerapan konsep lima tingkatan pencegahan penyakit (five level of prevention disease) pada penyakit akibat kerja, yakni:

a. Peningkatan kesehatan (health promotion). Misalnya: penyuluhan kesehatan dan keselamatan kerja (K3) pendidikan kesehatan, meningkatkan gizi yang baik, pengembangan kepribadian, perusahaan yang sehat dan memadai, rekreasi, lingkungan kerja yang memadai, penyuluhan perkawinan dan pendidikan seksual, konsultasi tentang keturunan dan pemeriksaan kesehatan periodik.

b. Perlindungan khusus (specific protection). Misalnya: imunisasi, hygiene perorangan, sanitasi lingkungan, serta proteksi terhadap bahaya dan kecelakaan kerja dengan menggunakan alat pelindung diri (APD) seperti helm, kacamata kerja, masker, penutup telinga (ear muff dan ear 
plug) baju tahan panas, sarung tangan, dan sebagainya.

c. Diagnosis (deteksi) dini dan pengobatan segera serta pembatasan titik-titik lemah untuk mencegah terjadinya komplikasi.

d. Membatasi kemungkinan cacat (disability limitation). Misalnya: memeriksa dan mengobati tenaga kerja secara komprehensif, mengobati tenaga kerja secara sempurna dan pendidikan kesehatan.

e. Pemulihan kesehatan (rehabilitation). Misalnya: rehabilitasi dan mempekerjakan kemali para pekerja yang menderita cacat. Sedapat mungkin perusahaan mencoba menempatkan keryawan-karyawan cacat di jabatan yang sesuai.

Upaya yang dapat dilakukan oleh perusahaan untuk mencegah PAK adalah sebagai berikut:

1. Menyingkirkan atau mengurangi risiko pada sumbernya, misalnya menggantikan bahan kimia yang berbahaya dengan bahan yang tidak berbahaya.

2. Mengurangi risiko dengan pengaturan mesin atau menggunakan APD.

3. Menetapkan prosedur kerja secara aman untuk mengurangi risiko lebih lanjut.

4. Menyediakan, memakai dan merawat APD

\section{Kesimpulan}

Keselamatan dan Kesehatan Kerja merupakan upaya perlindungan tenaga kerja dari bahaya, penyakit dan kecelakaan akibat kerja maupun lingkungan kerja. Penegakan diagnosis spesifik dan sistem pelaporan penyakit akibat kerja penting dilakukan agar dapat mengurangi dan atau bebas dari kecelakaan kerja dan penyakit akibat kerja yang pada akhirnya dapat meningkatkan efisiensi dan produktivitas kerja.

Pemahaman dan penerapan keselamatan dan kesehatan kerja (K3) masih kurang di perhatikan oleh pekerja formal maupun informal. Pada hal faktor K3 sangat penting dan harus diperhatikan oleh pekerja dan hal ini menjadi tanggung jawab bersama, perlu adanya kerja sama antara pemerintah, perusahaan dan pekerja agar terhindar dari Kecelakaan Akibat Kerja (KAK) dan Penyakit Akibat Kerja (PAK).

Pengalaman merupakan keseluruhan yang didapat seseorang dari peristiwa yang dialaminya, artinya bahwa pengalaman seseorang dapat mempengaruhi perilakunya dalam kehidupan pekerjaannya. Dengan demikian semakin lama masa kerja seseorang maka pengalaman yang diperolehnya semakin banyak yang memungkinkan perawat dapat bekerja lebih aman (Millah, 2008). 
Sedangkan menurut Cooper (2001) orang sering berperilaku tidak aman (unsafe action) karena orang tersebut belum pernah cedera saat melaksanakan pekerjaannya dengan tidak aman.

\section{Daftar Pustaka}

Efendi, F. dan Makhfudli. Keperawatan Kesehatan Komunitas Teori dan Praktik dalam Keperawatan. Jakarta: Penerbit Salemba Medika; 2009

Hanifa, Nadia, Dini, Titik., Respati, Yuli, Susanti. (2017). Hubungan Pengetahuan Dengan Upaya Penerapan K3 pada Perawat, Bandung Meeting on Global Medicine \& Health (BaMGMH), 1(1), 144-149.

Ibrahim,H., Damayanti, D.S., Amansyah, M.,\& Sunandar. (2017). Gambaran penerapan standar manajemen keselamatan dan kesehatan kerja rumah sakit di rumah sakit umum daerah haji Makassar. Al-Sisah, Public Health Science Journal, 9(2), 160-173.

Nursalam. (2014).

Manajemen Keperawatan, Aplikasi dalam Praktik Keperawatan Profesional. Edisi 4. Salemba Medika. Jakarta.
Pratiwi A D. (2012). Analisis faktor-faktor yang mempengaruhi tindakan tidak aman (unsafe act) pada pekerja di PT X. skripsi. FKM UI. Jakarta

Ratulangi, A, \& Josephus, J,B,S.(2013). Hubungan Pengetahuan, Sikap dengan Tindakan terhadap K3RS pada Perawat di Siloam Hospital Manado. Junal FKM Unsrat

Rudiyanto.(2014). Publik Berhak Tahu Kecelakaan Kerja. Jurnal Katiga, 54(8), 14-17

Salawati. Liza .(2017). Penyakit Akibat Kerja dan Pencegahan. Jurnal Kedokteran Syah Kuala, 15(2), 9195.

Simamora, R. H. (2011). ROLE CONFLICT OF NURSE RELATIONSHIP WITH PERFORMANCE IN THE EMERGENCY UNIT OF HOSPITALS RSD DR. SOEBANDI JEMBER. The Malaysian Journal of Nursing, 3(2), 23-32.

Simamora, R. H. (2020). Pelatihan Komunikasi Efektif untuk Meningkatkan Efikasi diri Perawat dalam Pelaksanaan Identifikasi Pasien. JURNAL ILMIAH KESEHATAN MASYARAKAT: Media Komunikasi Komunitas 
Kesehatan Masyarakat, 12(1), 49-

54.

Sulistiawat, Tukatman, Purwaningsih,

Nursalam. (2015). Analisis

Keselamatan dan Kesehatan Kerja

Perawat Dalam Penanganan

Pasien di Rumah Sakit Benyamin

Guluh Kabupaten Kolak,. Jurnal Ners, 10(2), 343-347

Salmawati, Lusia, Muh. Rasul, Muh.

Ryman Napirah. (2019). Faktor

yang Berhubungan dengan

Kejadian Kecelakaan Kerja pada

Perawat Di Ruangan IGD RSU

Anutapura Kota Palu. Jurnal

Kesehatan Masyaraka, 10(2), 104-

112. 